\title{
Relationship of the quality of life and depression in the elderly
}

Eka Suastika,

Ni Ketut Sri Diniari,

Cokorda Bagus Jaya Lesmana,

Luh Nyoman Alit Aryani,

Ni Ketut Putri Ariani,

Ida Aju Kusuma Wardani

Department of Psychiatry, Faculty of Medicine Udayana University/Sanglah General Hospital Bali, Indonesia
Cite this article:

Suastika E, Diniari NKS, Lesmana CBJ, Aryani LNA,Ariani NKP, Wardani IAK. Relationship of thequality of life and depression in the elderly.Journal of Clinical and Cultural Psychiatry.2020; I (2): 25-27.

\section{Corresponding author:}

Ni Ketut Ayu Diniari

Department of Psychiatry, Faculty of Medicine Udayana University/Sanglah General Hospital J. Kesehatan No I, Bali 80I I4, Indonesia sridiniari@ymail.com

\begin{abstract}
Background: A good quality of life in the elderly must be maintained because good quality of life is an optimal condition for the elderly to live their daily lives. Depression in the elderly will have a severe impact on physical, social life where it will reduce the quality of life. This study was conducted to assess the relationship of quality of life with depression in the elderly.
\end{abstract}

Method: This study uses a cross-sectional method, conducted in May-June 2019, using WHOQOL-BREf, GDS, AMT, ADL.

Results: A total of 195 elderly participated, average age 67 years, married 94.4 percent, mostly 45.1 percent did not go to school, ADL was found to be normal, there was moderate cognitive impairment as much as 13.3 percent, and depression 80 percent. There was a significant relationship between quality of life and depression (OR: 1.22; 95\% IK 1.02-3.97), which means that elderly people with poor quality of life have a higher risk of depression.

Conclusion: There is a significant negative correlation between the quality of life with depression, where the elderly with poor quality of life have a 1.22 times greater risk of depression.

Keywords: quality of life, depression, elderly

\section{Introduction}

Indonesia is currently an elderly population structural country due to its proportion of elderly which is 60 years and above (over 7 percent) which is shown on Susennas 2015 data, that the elderly is as much as 21.5 million people or about 8.43 percent of the entire population of Indonesia in 2015. The data shows that the elderly population tends to increase every year, so a). This year there are five provinces with the elderly population structure where elderly residents have reached 10 percent: DI Yogyakarta (13.90 percent), Central Java (12.46 percent), East Java (12.16 percent), Bali (10.79 percent) and West Sulawesi (10.37 percent). ${ }^{1}$

The deterioration in health status associated with aging will increase the risk of depression. The chronic disorders, specific sensory impairments, and significant limited functional capabilities increase the risk of depression among the elderly. Depression among the elderly often go undetected because of a decrease in executive functions and is seen as part of the aging process which results in worsening health status, low quality of life and more prominent use of health care. ${ }^{2}$

A good quality of life daily life of elderly to enjoy old age happily and meaningfully. ${ }^{3}$ Depression in the elderly will have serious impact on the social and physical life where this will lead to a decrease in quality of life, as well as causing elderly to be dependent to others. ${ }^{4,5}$ 


\section{Material and Methods}

This research is observational analytic research with cross-sectional because all variables which are independent variables and dependent variables are measured within the same period. It is called analytic for studying the relationship between quality of life and depression.

Sampling was carried out at 38 selected Posyandu in Puskesmas Tegalalang I region in Gianyar district in May-June 2019. The data were collected through direct interviews using a questionnaire and clinical examinations. Eligible samples in this study were samples that met the inclusion and exclusion criteria. Exclusion criteria, there is a mental disorder, or are ill during the study period, decreased cognitive function, elderly who are undergoing psychotropic treatment. Inclusion criteria, willing to fill out questionnaires, were present at the time of the study.

The quality of life of the sample was measured using a quality of life WHOQOL-BREF (World Health Organization Quality of LifeBREF) questionnaire. Depressive symptoms in the elderly in this study were measured using the Geriatric Depression Scale (GDS-15). Since 1983, it is best used to assess depression in healthy, ill elderly and elderly with mild to moderate cognitive impairment. GDS is also used for screening depression in the elderly in the community. The cognitive function of the elderly was assessed using the Abbreviated Mental Test Score (AMT). The elderly daily activities were assessed using the ADL scale (Activities Daily Life). Data processing was done manually by filling the observation form provided. The data was then processed using SPSS 20.

\section{Result}

Samples from this study are 195 elderly people within the working area of Tegalalang Public Health Center. Based on the characteristics of the sample, it can be determined that the mean age of the sample in this study is 67 years old, with 128 women $(65.7 \%)$ and 67 men (34.3\%). More samples have married status, which is 184 people (94.4\%), compared to the widow/widower as many as 11 people $(5.6 \%)$. Based on educational level, more samples are not in school, which is 88 people (45.1\%), only a fraction of the sample had received junior high school education, which is one person $(0.5 \%)$ (Table 1). This study assesses the quality of life using the World Health Organization Quality of Life-BREF scale that consists of four domains, which are physical, psychological, social relationships, and environment.

In Table 2, we can see that in the domain 1 (physical health) the majority of samples in this study have a moderate quality of life as many as 178 people $(91.3 \%)$, whereas the rest of 9 people have a good quality of life $(4.6 \%)$ and eight people have a poor quality of life (4.1\%). In domain 2 (psychological), more samples have a moderate quality of life that is 173 people ( $88.7 \%$ ), compared with people who have a poor quality of life that is six people (3.1\%), and good quality of life that is 16 people $(8.2 \%)$.
Table 1. Characteristics of the subjects.

\begin{tabular}{lcc}
\hline Characteristics & $\mathbf{N}$ & $\mathbf{\%}$ \\
\hline Age (years), mean \pm SD & $67.80 \pm 0.48$ & \\
Gender & & \\
Man & 67 & 34.3 \\
Woman & 128 & 65.7 \\
Marital status & & \\
Married & 184 & 94.4 \\
Widow/widower & 11 & 5.6 \\
Education level & & \\
No school & 88 & 45.1 \\
Do not finish elementary school & 43 & 22.1 \\
Elementary & 63 & 32.3 \\
Junior high & 1 & 0.5 \\
Employment Status & & \\
Employed & 144 & 73.8 \\
Unemployed & 51 & 26.2 \\
Activity Daily Living (ADL) & & \\
Normal & 195 & 100 \\
Abnormal & 0 & 0 \\
Cognitive impairment & & \\
Moderate cognitive impairment & 26 & 13.3 \\
Normal & 169 & 86.7 \\
Depression & & \\
Depression & 156 & 20 \\
Normal & 39 & \\
\hline
\end{tabular}

Based on domain 3 (social relationships), more samples have moderate quality of life that is 146 people $(74.9 \%)$, one people $(0.5 \%)$ has very poor quality of life, 25 people (12.8 \%) have poor quality of life, 19 people $(9.7 \%)$ have good quality of life, and four people $(2.1 \%)$ have very good quality of life. Only in the social relations domain spectrum, it's found that the quality of life varies greatly.

Table 2. Quality of life assessment.

\begin{tabular}{lcc}
\hline Overall Quality of Life & $\mathrm{N}$ & $\%$ \\
\hline Poor quality of life & 5 & 2.6 \\
Moderate quality of life & 186 & 95.4 \\
Good quality of life & 4 & 2.1 \\
Domain 1 (Physical Health) & & \\
Poor & 8 & 4.1 \\
Moderate & 178 & 91.3 \\
Good & 9 & 4.6 \\
Domain 2 (Psychological) & & \\
Poor & 6 & 3.1 \\
Moderate & 173 & 88.7 \\
Good & 16 & 8.2 \\
Domain 3 (Social Relations) & & \\
Very poor & 1 & 0.5 \\
Poor & 25 & 12.8 \\
Moderate & 146 & 74.9 \\
Good & 19 & 9.7 \\
Very good & 4 & 2.1 \\
Domain 4 (Environment) & & \\
Poor & 17 & 8.7 \\
Moderate & 147 & 75.4 \\
Severe & 31 & 15.9 \\
\hline
\end{tabular}

Based on domain 4 (environment), more samples have a moderate quality of life that is 147 people $(75.4 \%), 17$ people $(8.7 \%)$ have a poor quality of life, and 31 people (15.9\%) have a good quality of life.

Table 3. Odds ratio from depression and quality of life.

\begin{tabular}{cccc}
\hline Variables & \multicolumn{3}{c}{ Quality of life (OR(CI95\%)) } \\
\cline { 2 - 4 } & Poor & Moderate & Good \\
\hline Depression & $1.22(1.02-3.97)$ & $1.42(0.14-14.42)$ & $0.22(0.12-3.97)$ \\
\hline
\end{tabular}


We used logistic regression modeling to see the relationship between the quality of life and depression in the elderly. We found that depression is a risk factor of the occurrence of poor quality of life (OR: 1.22; CI 95\% 1.02-3.97) and there is a significant relationship between quality of life and depression, in which elderly with poor quality of life had 1.22 times higher risk to experience depression (Table 3).cannot be controlled. Last, the writer used BAI as an anxiety questionnaire and PSQI as a sleep quality questionnaire. The use of other questionnaires to assess anxiety and sleep quality in other studies can be a challenging comparison.

\section{Discussion}

In this study, we found that the average age of the study sample was 67 years old, with women more than men, and people with married status is more than the widow/widower, has no dependency in $\mathrm{ADL}$, and the prevalence of depression in this study was $80 \%$.

A survey on the quality of life in geriatrics in 15 countries in Europe involving 13.828 respondents found that the average age in the geriatric population in the study was 75.9 years old, the majority of the geriatric population who has no limitation on ADL were 71,516 people $(78.6 \%) .{ }^{6}$ There is a characteristic difference between that study and this study, with a mean value of age in this study, tend to be lower. This is probably caused by a difference in the characteristics of developed countries and developing countries based on life expectancy numbers. Indonesia's current life expectancy number reached 68 years old.

In this study, the quality of life was measured using the WHO quality of life questionnaire BREF where the quality of life can be grouped into four main domains of physical health, psychological, environmental, and social relationships.

A study conducted by Lok et al. ${ }^{6}$ which assessed the quality of life in the elderly population with depressive symptoms, used the value of the quality of life for aspects of physical health, physical role, pain, health perception, vitality, social functioning, emotional role, and mental health. It can be seen that there are three aspects with the lowest score that is general health, social functioning, and mental health. ${ }^{7}$ Higher scores indicate better quality of life. Research by Lok et al. found that quality of life score by lower social function is similar to current research finding that the quality of life based on social functions has $12.8 \%$ ( 25 people) in the category of poor social functioning, and one person $(0.5 \%)$ with very poor social functioning quality. ${ }^{7}$

This study assessed depression with GDS 15 questionnaire and found a total of 156 samples were depressed (80\%), and 20\% were not depressed. This is similar to the study by Leles et al. ${ }^{8}$ in Brazil, stating that late-life depression occurs in 1 out of 10 elderly. Depression is also associated with a variety of clinical factors and sociodemographic factors. ${ }^{8}$

This study found a negative correlation between the quality of life and depression, the worse the quality of life, the higher the level of depression in the elderly. Research by Unalan et al. found a strong negative correlation $(r=-0.77)$ between depression (assessed using the GDS questionnaire) and also the quality of life (assessed using the WHO-QoL-BREF questionnaire). The higher the depression scores (indicating a more severe level of depression in a person) will be lower. ${ }^{9}$

This study did not assess related chronic diseases in the elderly. Also, the nature of the cross-sectional study provides a causal relationship obtained in this study is lower compared to a cohort study. Assessment of family factor and the role of the environment was also not carried out in this study, so other factors beyond the characteristics of this research that affects the quality of life are a lot.

\section{Conclusion}

This study did not assess related chronic diseases in the elderly. Also, the nature of the cross-sectional study provides a causal relationship obtained in this study is lower compared to a cohort study. Assessment of family factor and the role of the environment was also not carried out in this study, so other factors beyond the characteristics of this research that affects the quality of life are a lot.

\section{Acknowledgement}

The authors report no conflict of interests.

\section{Reference}

1. Beaumont JG. Kenealy PM. Quality of life perceptions and social comparisons in healthy old age. Ageing and Society. 2004;24(5):755-69.

2. Schorr AV, Khalaila R. Aging in place and quality of life among the elderly in Europe: A moderated mediation model. Archives of Gerontology and Geriatrics. 2018;77:1-9. DOI: 10.1016/j.archger.2018.04.009

3. Unalana D, Gocerb S, Basturkc M, et al. Coincidence of low social support and high depressive score on quality of life in elderly. European Geriatric Medecine. 2015;6(4):319-324. DOI: 10.1016/j.eurger.2015.02.009

4. Akosile CO, Mgbeojedo UG, Maruf FA, et al. Depression, functional disability and quality of life among Nigerian older adults: Prevalences and relationships. Arch Gerontol Geriatr. 2018 Jan;74:39-43. DOI: 10.1016/j.archger.2017.08.011

5. Chan SW, Shoumei JI, Thompson DR, et al. A cross-sectional study on the health related quality of life of depressed Chinese older people in Shanghai. Int J Geriatr Psychiatry. 2006;21(9):883-9.

6. Lok N, Lok S, Canbaz M. The effect of physical activity on depressive symptoms and quality of life among elderly nursing home residents: Randomized controlled trial. Arch Gerontol Geriatr. 2017;70:92-98. DOI: 10.1016/j.archger.2017.01.008

7. Lu C, Yuan L, Lin W, et al. Depression and resilience mediates the effect of family function on quality of life of the elderly. Arch Gerontol Geriatr. 2017;71:34-42. DOI: 10.1016/j.archger.2017.02.011

8. Leles da Costa DF, Teixeira AL, Cerqueira Guimarães H, et al. Prevalence of latelife depression and its correlates in a community-dwelling low-educated population aged 75+ years: The Pietà study. J Affect Disord. 2019;242:173-179. DOI 10.1016/j.jad.2018.08.012

9. Li C, Jiang S, Zhang X. Intergenerational relationship, family social support, and depression among Chinese elderly: A structural equation modeling analysis. $J$ Affect Disord. 2019;248:73-80. DOI: 10.1016/j.jad.2019.01.032 